\title{
A Study of English Listening Strategies of Vocational College Non-English Majors in China*
}

\author{
JIA Li-ping, WANG Zhao-hui \\ Chengdu Textile College, Chengdu, China
}

\begin{abstract}
According to English Curriculum Requirements for Higher Vocational Education formulated by Ministry of Education of China, teaching objectives of vocational college English course is to enhance students' language proficiency, enable students to master effective learning approaches and strategies, and cultivate students' ability to use English in workplace. Since 1970s, a wide range of studies on learning strategies from different aspects and perspectives have been conducted at home and abroad. However, little related research has done on that of vocational college students. So, this paper presents an empirical study of listening strategies preferred by non-English majors of vocational college in China to provide some pedagogical implications for teachers to improve the students' autonomous learning abilities, learning efficiency, and English proficiency.
\end{abstract}

Keywords: listening strategies, listening proficiency, vocational college, correlation

\section{Introduction}

With the rapid development of cognitive psychology in 1970s, researchers on second language acquisition gradually shifted their focus from language teaching to language learning. Since the beginning of the 1970s, great emphasis has been attached to the language learning process and the factors affecting individual differences in language learning. Language learning strategies started to attract the attention of researchers and were brought under systematic study in this research background.

According to second language acquisition theories, input of language is the basic condition for language learning. Therefore, listening comprehension plays an important part in language teaching and learning. However, the majority of research focuses on activities such as reading and writing skills. Little attention has been paid to listening and speaking skills.

With the development of higher education in China, vocational college students consist of a large group of EFL learners in China. According to the latest English Curriculum Requirements for Higher Vocational Education, the objective of higher vocational English course is to cultivate students' ability to use English in workplace, especially listening and speaking skills, in order to lay the necessary foundation for enhancing competitiveness in employment and sustainable development in the future. Thus it can be seen that improving

\footnotetext{
* Acknowledgements: The study has been supported by the Project of Higher Education and Teaching Research, Chengdu Textile College, China (No. [2012]01-17).

JIA Li-ping, lecturer, M.A. in Applied Linguistics, Foreign Languages School, Chengdu Textile College.

WANG Zhao-hui, professor, M.A. in Education, Foreign Languages School, Chengdu Textile College.
} 
students' listening ability and learning strategies has risen to top priority in English teaching.

Since different researchers would like to focus on different characteristics of learning strategies, it is not easy to define and classify learning strategies. According to the function of language learning, O'Malley and Chamot (1985) classified learning strategies into three categories: metacognitive, cognitive, and social-affective strategies based on psychological studies in cognition. According to O'Malley and Chamot's (1990) classification of learning strategies, Vandergrift $(1996,1997)$ classified listening strategies into three categories: metacognitive strategy, cognitive strategy, and social-affective strategy. The substrategies of metacognitive strategy include planning, evaluation problem identification and monitoring. Cognitive strategy's substrategies are elaboration, inference, translation, repetition, transfer, deduction, summarization, note-taking, substitution, resourcing, and grouping. And social-affective strategy consists of lowering anxiety, taking emotional temperature, self-encouragement, questioning for clarification and cooperation.

This study, mostly based on Vandergrift's classification, attempts to identify the listening strategy used by non-English major students in vocational college in China, explore the relationship between listening proficiency and listening strategies, and provide some implications for English teachers to develop their students' listening strategy use and improve students' listening proficiency.

\section{The Study}

\section{Research Questions}

This present study focuses on the listening strategy used by non-English major students in vocational college in China. Three research questions guide the study are:

(1) What English listening strategies do the vocational college students use?

(2) Is there any correlation between listening strategy use and listening proficiency?

(3) Are there any differences in the use of listening strategies between good learners and poor learner? If so, what are they?

\section{Research Design}

Subjects. The subjects in the study are 120 first-year vocational college non-English majors from three departments of Chengdu Textile College. All participants have learned English for six and a half year with similar learning environment. Their average age is 19 , ranging from 18 to 21 . As for the students who have studied in college for one semester, they have adapted themselves to the study and living in college and formed their own learning methods and habits.

Instruments. The following instruments are used in the study:

(1) English listening strategy questionnaire;

(2) Listening comprehension test (Sichuan College English Test, Band3/SCET-3);

(3) Interview.

Listening strategy questionnaire. The questionnaire used in this study is based on Oxford's (1990) Strategy Inventory for Language Learning (SILL), O'Malley \& Chamot's (1990) and WEN's (1995) framework. It is used to identify listening strategies use of the students.

There are two parts in the listening strategy questionnaire. Part one is about students' personal information, such as name, gender, age, major, etc. It also includes six questions about their opinions of English learning, the 
status of listening among the four skills (listening, speaking, reading, and writing), and their attitude towards listening strategies. Part two is made up of 48 statements concerning listening strategies with three categories: metacognitive, cognitive, and social-affective strategy.

All the strategy items are rated on a five-point scale (Likert Scale) ranging from 1 (this statement is never true of me) to 5 (this statement is always true of me).

Listening comprehension test. A listening comprehension test is carried out to differentiate the listening proficiency of the subjects. SCET-3 is a provincial standardized English test and had moderate difficulty for the students of vocational college. To make it more reliable and convincing, the listening comprehension part of a SCET-3 model test paper includes three sections, short conversations, long conversations, and a passage for spot dictation.

Interview. According to listening comprehension test scores of the participants, five high-proficient students and five low-proficient students are interviewed to find out the differences between good language learners and poor ones in the use of listening strategies and also explore the relationship between the students' listening strategy use and their English listening proficiency.

\section{Data Collection and Analysis}

The research was conducted in May 2015.

First of all, all the participants took the model listening comprehension test.

Secondly, the participants were given half an hour to complete the questionnaire after finishing the model test. Students were told the data collected would be used only for research so that they could do the survey as honestly as possible.

Thirdly, five high-proficient students and five low-proficient students were interviewed individually for further information.

Finally, all the data was collected, and was processed by SPSS19.0, then was analyzed as answers to the research questions.

\section{Results and Discussion}

\section{Students' Attitude Towards English Learning and Listening Strategies}

It is quite necessary to have a general idea of students' attitude towards English learning and listening strategies before we are going to analyze the overall strategy use.

Table 1

Students' Attitude Towards English Learning

\begin{tabular}{llllll}
\hline & \multicolumn{4}{c}{ Successful foreign language learners always have language aptitude. } & Total \\
\cline { 2 - 5 } Option & Disagree & Maybe & Agree & Completely agree & number \\
\hline \multirow{2}{*}{ Total } & 18 & 35 & 61 & 6 & 120 \\
& $15.0 \%$ & $29.2 \%$ & $50.8 \%$ & $5.0 \%$ & $100.0 \%$ \\
\hline
\end{tabular}

In general, over half of the students agree that a successful foreign language learner always has language aptitude. 
Table 2

Students' Attitude Towards Listening Strategies

\begin{tabular}{llllll}
\hline & \multicolumn{4}{c}{ It is important to choose useful listening strategies in listening learning. } & Total \\
\cline { 2 - 6 } Option & Disagree & Maybe & Agree & Completely agree & number \\
\hline \multirow{2}{*}{ Total } & 3 & 6 & 65 & 46 & 120 \\
& $2.5 \%$ & $5 \%$ & $54.2 \%$ & $38.3 \%$ & $100.0 \%$ \\
\hline
\end{tabular}

Generally speaking, most of the students hold a positive attitude towards listening strategies.

Table 3

Students' Attitude Towards the Importance of Listening Among the Four Skills

\begin{tabular}{llllll}
\hline & \multicolumn{4}{c}{ What is the position of listening among the four language skills? } & Total \\
\cline { 2 - 5 } Option & First & Second & Third & Fourth & number \\
\hline Frequency & 48 & 61 & 7 & 4 & 120 \\
Percent & $40.0 \%$ & $50.8 \%$ & $5.8 \%$ & $3.4 \%$ & $100.0 \%$ \\
\hline
\end{tabular}

In the survey, students are required to rank listening among the four skills in the order of importance. Since most of the students regard listening as an important language skill, they will definitely make a great effort to acquire the knowledge of listening strategies in order to improve their listening proficiency.

\section{Type of English Listening Strategies Use of Vocational College Students}

Descriptive statistics is employed to analyze listening strategies used by the objectives. Oxford (1990) divided the frequency of strategies use into three levels, which are high, medium, and low. To be specific, if the mean is greater than or equals to 3.5 , it is regarded as high frequency; the mean comes within 2.5-3.4, it is medium frequency; and if lower than 2.5 , it is considered as low frequency.

Table 4 provides an overview of the three categories of listening strategy use of the whole 120 participants. The overall mean for the samples is 2.9220. Following Oxford's frequency scale, the frequency of the total listening strategy use falls in the range of 2.5-3.4, so we can see the students using listening strategies are in the medium level. To some extent, the results are related to the students' beliefs on language learning. Most of the students emphasize the role of language aptitude in language learning, which may affect students' motivation to a large extent (see Table 1). More than $92 \%$ of the students approve the importance of choosing useful listening strategies in listening learning (see Table 2).

Table 4

Descriptive Statistics of Three Categories of Listening Strategy Use

\begin{tabular}{llll}
\hline Types of strategy & $\mathrm{N}$ & Mean & Std. Deviation \\
\hline Metacognitive & 120 & 2.9667 & .59585 \\
Cognitive & 120 & 3.0940 & .58450 \\
Social-affective & 120 & 2.7052 & .62988 \\
Total & 120 & 2.9220 & .54841 \\
\hline
\end{tabular}

Moreover, as shown in Table 4, cognitive strategies are used more, followed by metacognitive, and the social-affective strategies are often ignored by the students.

To obtain more specific information, the mean of the substrategies use of the three categories is demonstrated in the Tables 5-7. 
Table 5

Descriptive Statistics of Listening Substrategies: Metacognitive Strategy

\begin{tabular}{llll}
\hline Types of strategy & $\mathrm{N}$ & Mean & Std. Deviation \\
\hline Finding out about language & 120 & 2.8083 & .66003 \\
learning & 120 & 3.11 & .933 \\
Directed attention & 120 & 2.97 & .809 \\
Functional planning & 120 & 3.07 & 1.067 \\
Selective attention & 120 & 3.1467 & .77600 \\
Self-management & 120 & 3.2458 & .86723 \\
Self-monitoring & 120 & 2.90 & .883 \\
Self-evaluation & & & \\
\hline
\end{tabular}

As shown in Table 5, within the metacognitive strategy, self-monitoring (mean $=3.2458$ ) is the one used in high frequency, followed by self-management (mean $=3.1467$ ). Self-monitoring means to "checking, verifying, or correcting one's comprehension or performance in the process of a listening task" (Vandergrift, 1997, p. 392), and self-management refers to understanding the conditions for helping language learning and striving to create those conditions. The frequent use of these two strategies indicates that the students have the ability to adjust the content of listening, which is due to the development of autonomous learning methodology in recent years. As reported in the interview, the good students could check, verify, and correct their listening comprehension, while the poor students may not be aware of their misunderstanding, even if they sometimes could, they just do not know the way of correcting.

Table 6

Cognitive Strategy

\begin{tabular}{llll}
\hline Types of strategy & $\mathrm{N}$ & Mean & Std. Deviation \\
\hline Resourcing & 120 & 3.0083 & .97873 \\
Repetition & 120 & 3.22 & .945 \\
Grouping & 120 & 2.92 & .992 \\
Deduction & 120 & 2.99 & .921 \\
Analyzing & 120 & 2.88 & 1.063 \\
Imagery & 120 & 2.97 & .978 \\
Auditory representation & 120 & 2.94 & 1.110 \\
Keyword method & 120 & 2.25 & 1.038 \\
Elaboration & 120 & 3.0458 & .81991 \\
Transfer & 120 & 3.10 & 1.056 \\
Inference & 120 & 3.3286 & .75197 \\
Note taking & 120 & 3.2967 & .75852 \\
Summarizing & 120 & 2.86 & 1.007 \\
Recombination & 120 & 2.79 & 1.003 \\
Translation & 120 & 3.27 & 1.111 \\
Using formulas and patterns & 120 & 2.92 & .970 \\
Practicing naturally & 120 & 2.67 & 1.162 \\
\hline
\end{tabular}

As for the cognitive category, the inference strategy (mean $=3.3286$ ) is the most high frequency strategy used by the subjects, followed by note-taking (mean $=3.2967$ ) and translation (mean $=3.27$ ), while the keyword method strategy $($ mean $=2.25)$ is used least frequently. 
The result indicates that students can usually use contextual knowledge to assist their listening comprehension. Students also prefer note-taking strategy. It motivates listeners to store content into long-term memory, but it also hinders the comprehension of the incoming information. During the interview, some students report that they get used to take notes during study, which shows attentive and serious. Just as the saying goes "the worst pen is better than the best memory".

However, keyword method is the lowest among the cognitive strategies. Though it is quite popular in Western countries, Chinese students seldom use it.

Table 7

Social-Affective Strategy

\begin{tabular}{llll}
\hline Types of strategy & $\mathrm{N}$ & Mean & Std. Deviation \\
\hline Interest cultivation & 120 & 3.27 & 1.113 \\
Lowering anxiety & 120 & 3.29 & 1.141 \\
Self-encouragement & 120 & 2.96 & 1.056 \\
Empathizing with others & 120 & 3.06 & 1.056 \\
Question for clarification & 120 & 2.54 & .883 \\
Cooperation & 120 & 3.02 & .970 \\
\hline
\end{tabular}

With regard to the social-affective strategy, students are inclined to use the lowering anxiety strategy (mean $=3.29$ ) the most, and interest cultivation (mean $=3.27$ ) is the second, while questioning for clarification (mean = 2.54 ) is the least frequently used strategy. In order to get good grade in English test, students would think of ways to ease their tension, such as taking a deep breath. Questioning for clarification belongs to the social strategy category. This result may relate to Chinese culture that asking questions may be a shame or look ignorant in front of the public. Most of the students reported in the interview that they would like to try to solve the problems they have encountered in listening comprehension on their own. If they could not find a solution, they would just pretend to understand that they really do not and neglect the difficulties for the fear of losing face.

\section{Correlation Between Listening Strategy Use and Listening Proficiency}

To investigate the correlations existing between the listening strategy use and listening proficiency, the analysis of Pearson Correlation is conducted in the study.

As the shown in the above, metacognitive, cognitive, and social-affective strategies are correlated with the listening scores significantly.

Table 8

The Correlation Between Listening Strategies and Listening Scores

\begin{tabular}{llllll}
\hline & & $\begin{array}{l}\text { Metacognitive } \\
\text { strategies }\end{array}$ & Cognitive strategies & $\begin{array}{l}\text { Social-affective } \\
\text { strategies }\end{array}$ & Listening scores \\
\hline $\begin{array}{l}\text { Metacognitive } \\
\text { strategies }\end{array}$ & Pearson correlation & 1 & $.783^{* *}$ & $.689^{* *}$ & $.456^{* *}$ \\
& Sig. (2-tailed) & & .000 & .000 & .000 \\
& $\mathrm{~N}$ & 120 & 120 & 120 & 120 \\
Cognitive strategies & Pearson correlation & $.783^{* *}$ & 1 & $.753^{* *}$ & $.437^{* *}$ \\
& Sig. (2-tailed) & .000 & & .000 & .000 \\
& $\mathrm{~N}$ & 120 & 120 & 120 & 120 \\
\hline
\end{tabular}


(table 8 continued)

\begin{tabular}{llllll}
\hline & & $\begin{array}{l}\text { Metacognitive } \\
\text { strategies }\end{array}$ & Cognitive strategies & $\begin{array}{l}\text { Social-affective } \\
\text { strategies }\end{array}$ & Listening scores \\
\hline $\begin{array}{l}\text { Social-affective } \\
\text { strategies }\end{array}$ & Pearson correlation & $.689^{* *}$ & $.753^{* *}$ & 1 & $.369^{* *}$ \\
& Sig. (2-tailed) & .000 & .000 & & .000 \\
& $\mathrm{~N}$ & 120 & 120 & 120 & 120 \\
Listening scores & Pearson correlation & $.456^{* *}$ & $.437^{* *}$ & $.369^{* *}$ & 1 \\
& Sig. (2-tailed) & .000 & .000 & .000 & 120 \\
\hline
\end{tabular}

Notes. ${ }^{*}$ Correlation is significant at the 0.01 level (2-tailed).

From the statistics in Table 8, we can see the correlation between metacognitive strategies and listening test score is strong $(r=0.456, p<0.01)$ and the correlation between cognitive strategies and listening score is also quite strong $(\mathrm{r}=0.437, \mathrm{p}<0.01)$. Compared with the previous two strategies, the correlation between social-affective strategies and listening score is weaker $(r=0.369, p<0.01)$, but still significant.

It is also demonstrated in Table 8 that cognitive strategies have a very strong correlation with metacognitive strategies $(\mathrm{r}=0.783, \mathrm{p}<0.01)$. Metacognitive strategies and cognitive strategies are often used together, supporting each other.

The correlation between social-affective strategies and listening score is relatively weaker than the other two, and social-affective strategies influence the students' listening performance at low level. As S. Krashen (1982) stated in "Affective-Filter Hypothesis", affective factors may restrain or facilitate the process from language input to language acquisition device (LAD). Confidence and calmness are beneficial for learners in the process of language acquisition. This indicates that the more one depends on social-affective factors, the better the listening performance is.

From the interview with good learners and poor learners, the correlation between listening strategy use and listening proficiency is further proved. As the poor learners report, they have little idea of what listening strategies are. In listening comprehension, they hardly use the clues as their background knowledge, context, speakers' intonation, etc., to promote their listening comprehension, instead, they just skip over the difficulties they came across or give up after a few attempts. Moreover, they are always afraid of listening and get nervous easily during listening comprehension tests. On the contrary, good learners say that they are familiar with some of the learning strategies, and will apply them in listening comprehension intentionally, appropriately, and flexibly, such as guessing the meaning of new words with the context, inferring the theme from the repeated words, predicting the filling information from context when doing spot dictation, analyzing and correcting the mistakes, and so on, which would contribute to their listening proficiency.

\section{Comparison of Listening Strategies Use Between Good Learners and Poor Learners}

Based on the results of Independent Samples T-tests, the differences of the three categories of listening strategies between the two groups are shown in Table 9. 
Table 9

Comparison of Listening Strategies between Two Proficient Groups

\begin{tabular}{llllll}
\hline Variables & $\begin{array}{l}\text { Mean } \\
\text { (Good learners) }\end{array}$ & $\begin{array}{l}\text { Mean } \\
\text { (Poor learners) }\end{array}$ & Mean difference & $\mathrm{T}$ & Sig. (2-tailed) \\
\hline Metacognitive strategies & 3.1333 & 2.5867 & .54667 & 3.715 & $.000^{* *}$ \\
Cognitive strategies & 3.2800 & 2.7507 & .52933 & 3.425 & $.001^{* *}$ \\
Social-affective strategies & 3.2583 & 2.6458 & .61250 & 3.528 & $.001^{* *}$ \\
\hline
\end{tabular}

Notes. ** Correlation is significant at the 0.01 level (2-tailed).

As the data from Table 9, good learners display higher frequency than poor learners in using metacognitive, cognitive, and social-affective strategies. And the differences in the use of these three categories of listening strategies in listening comprehension are significant.

As far as metacognitive strategies are concerned, there are significant differences at the level 0.01 in finding out about language learning, self-management, and monitoring strategies (see Table 10).

Table 10

Comparison of Metacognitive Strategies Between Two Proficient Groups

\begin{tabular}{|c|c|c|c|c|c|}
\hline Variables & $\begin{array}{l}\text { Mean } \\
\text { (Good learners) }\end{array}$ & $\begin{array}{l}\text { Mean } \\
\text { (Poor learners) }\end{array}$ & Mean difference & $\mathrm{T}$ & Sig. (2-tailed) \\
\hline $\begin{array}{l}\text { Finding out about language } \\
\text { learning }\end{array}$ & 2.9917 & 2.2583 & .73333 & 4.382 & $.000 * *$ \\
\hline Directed attention & 3.40 & 2.97 & .433 & 1.968 & .054 \\
\hline Functional planning & 2.73 & 2.77 & -.033 & -.143 & .887 \\
\hline Selective attention & 3.10 & 3.00 & .100 & .341 & .734 \\
\hline Self-management & 3.5467 & 2.6867 & .860 & 3.386 & $.001 * *$ \\
\hline Self-monitoring & 3.6000 & 2.75 & .850 & 3.491 & $.001 * *$ \\
\hline Self-evaluation & 2.87 & 2.60 & .267 & 1.127 & .264 \\
\hline
\end{tabular}

Notes. $* *$ Correlation is significant at the 0.01 level (2-tailed).

Good learners have much better command of language knowledge and skills than poor learners. Good learners can monitor and make plans for English learning. They set clear goal in improving their listening proficiency, and create the environment for practice, such as having conversation with native speakers. However, poor learners are afraid of listening activities. They have no idea how to improve their listening ability. Without a specific aim, they do nothing to practice listening in spare time.

In the process of listening, good learners would like to concentrate their mind on the listening activity and ignore irrelevant distracters. However, the poor learners seem to be influenced by their anxiety or other interference factors easily. Moreover, during listening practice, good listeners could give attention to the mistakes in listening comprehension and analyze the mistakes for progress, while poor listeners could not.

Table 11

Comparison of Cognitive Strategies Between Two Proficient Groups

\begin{tabular}{llllll}
\hline Variables & $\begin{array}{l}\text { Mean } \\
\text { (Good learners) }\end{array}$ & $\begin{array}{l}\text { Mean } \\
\text { (Poor learners) }\end{array}$ & Mean difference & T & Sig. (2-tailed) \\
\hline Resourcing & 2.7833 & 2.8500 & -.06667 & -.231 & .818 \\
Repetition & 3.57 & 3.00 & .567 & 2.134 & .037 \\
Grouping & 2.77 & 2.33 & .433 & 1.844 & .071 \\
\hline
\end{tabular}


(table 11 continued)

\begin{tabular}{llllll}
\hline Variables & $\begin{array}{l}\text { Mean } \\
\text { (Good learners) }\end{array}$ & $\begin{array}{l}\text { Mean } \\
\text { (Poor learners) }\end{array}$ & Mean difference & $\mathrm{T}$ & Sig. (2-tailed) \\
\hline Deduction & 3.23 & 2.77 & .467 & 1.614 & .112 \\
Analyzing & 3.20 & 2.33 & .867 & 3.496 & $.001^{* *}$ \\
Imagery & 3.00 & 2.67 & .333 & 1.262 & .212 \\
Auditory representation & 2.60 & 3.33 & -.733 & -2.233 & .029 \\
Keyword method & 2.34 & 2.19 & .152 & 1.644 & .101 \\
Elaboration & 3.1167 & 2.8833 & .23333 & 1.114 & .270 \\
Transfer & 3.37 & 2.30 & 1.067 & 4.158 & $.000^{* *}$ \\
inference & 3.6429 & 2.9143 & .72857 & 3.850 & $.000^{* *}$ \\
note taking & 3.4167 & 2.8667 & .55000 & 2.845 & .006 \\
summarizing & 3.20 & 2.33 & .867 & 3.261 & $.002 *$ \\
recombination & 3.13 & 2.20 & .933 & 3.489 & $.001 * *$ \\
translation & 3.50 & 3.33 & .167 & .512 & .611 \\
using formulas and patterns & 3.47 & 2.63 & .833 & 3.016 & $.004 *$ \\
practicing naturally & 3.23 & 2.33 & .900 & 2.798 & .007 \\
\hline
\end{tabular}

Notes. ** Correlation is significant at the 0.01 level (2-tailed); * correlation is significant at the 0.05 level (2-tailed).

There are significant differences between the two groups in inference, analyzing, transfer, recombination, summarizing, using formulas and patterns strategies.

Good learners are having good learn habits and have formed their own effective learning methods, which is quite important for improving their language proficiency. And they are good at applying appropriate cognitive strategies. Take transfer for example. Good learners can apply the skills of reading comprehension to listening practice, such as the use of their background knowledge and the context for listening comprehension. However, poor learners may not use a particular skill quite flexibly and appropriately in different aspects of language learning. Inference is another important difference between the two groups. From the later interview, good learners state that it is easier and more convenient for them to make inference in the listening comprehension according to the context, speaker's intonation, transitional words, relationship of the speakers, etc.

Table 12

Comparison of Social-Affective Strategies Between Two Proficient Groups

\begin{tabular}{|c|c|c|c|c|c|}
\hline Variables & $\begin{array}{l}\text { Mean } \\
\text { (good learners) }\end{array}$ & $\begin{array}{l}\text { Mean } \\
\text { (poor learners) }\end{array}$ & Mean difference & $\mathrm{T}$ & Sig. (2-tailed) \\
\hline Interest cultivation & 3.43 & 2.80 & .633 & 2.263 & .027 \\
\hline Lowering anxiety & 3.33 & 2.40 & .933 & 3.663 & $.001 * *$ \\
\hline Self-encouragement & 3.17 & 2.60 & .567 & 1.925 & .059 \\
\hline Empathizing with others & 3.09 & 2.50 & .591 & 2.619 & .015 \\
\hline Question for clarification & 2.97 & 2.33 & .643 & 2.373 & .021 \\
\hline Cooperation & 3.13 & 2.37 & .767 & 3.319 & $.002 *$ \\
\hline
\end{tabular}

Notes. $* *$ Correlation is significant at the 0.01 level (2-tailed); $*$ correlation is significant at the 0.05 level (2-tailed).

As for social-affective strategy category, it is unsurprising that good learners use the affective strategies much more than poor learners.

Good learners can successfully control their affection and lower anxiety while listening. As one of them says in the interview, she is confident about her English proficiency. When she meets some difficulties, she can make 
self-adjustment actively and calm down. On the contrary, poor learners could hardly release tension in listening comprehension, unless they do not care about the result.

Furthermore, good learners focus on cooperative learning, which promotes a greater use of learning strategies than individual learning. However, poor learners feel ashamed to communication with teachers or classmates in language learning and they do not study English with others, because they are afraid of being looked down upon.

\section{Conclusion}

\section{Major Findings}

To conclude, higher vocational college students' use of English listening strategies is not satisfied, which is at a medium frequency level. The students prefer to use cognitive strategies most often, followed by metacognitive strategies, and social-affective strategies. As for cognitive strategies, they incline to use the inference strategy mostly, followed by note-taking, translation, and the keyword method strategy. With regard to metacognitive strategies, they prefer to use self-monitoring strategy most often, followed by self-management. For social-affective strategies, they tend to use the lowering anxiety strategy most frequently, and followed by interest cultivation, while the least frequently used is questioning for clarification.

According to the analysis of the statistics, the correlation between listening strategies and listening proficiency is significant. Metacognitive strategy and cognitive strategy are strongly correlated with listening proficiency, while the correlation between social-affective strategies and listening proficiency is relatively weaker. And listening strategies have a significant effect on improving the listening proficiency of the students from higher technical and vocational college.

The differences in the use of the three categories of listening strategies between good learners and poor learners are significant. As for the specific substrategies in metacognitive category, good learners use self-monitoring, self-management and find out about language learning significantly more often than poor learners. Within the cognitive strategy category, good learners employ the substrategies as inference, analyzing, transfer, recombination, summarizing, using formulas and patterns more often than poor learners. And in the social-affective strategy category, the using of lowering anxiety and cooperation strategies of good learners is significantly frequent than poor learners.

\section{Pedagogical Implications}

Based on the findings, it is essential and urgent to cultivate students' awareness in facilitating their listening proficiency by the use of listening strategies and offer them appropriate training courses. Some pedagogical implications for improving students' listening strategies are recommended as follows:

Firstly, enhance students' awareness of applying metacognitive strategies and autonomous learning ability. Teachers should help students to set a goal for gaining a higher level of English proficiency as soon as they enter college and make a plan for improving English listening comprehension. Based on the long-term goals, students can set down their short-term goals according to their own English level. For example, starting from listening to short conversations in two or three sentences to long conversations, from VOA Special English to Ted talks. After a period of practice, students are required to evaluate the implementation of their plan and check whether they have made any progress. Besides, it is advisable for teachers to train the students to monitor their listening 
comprehension of English materials. Before listening, it is essential for teachers to distribute some time for brainstorming and guide the students to get prepared for listening materials. While listening, teachers can design some tasks for different purposes to lead the students to monitor their understanding of listening materials and their degree of concentration. After listening, students should learn to evaluate whether their listening skills are properly applied. What is mentioned above denotes that teachers should arouse students' awareness of metacognitive strategies and lay stress on their training. Students should take a positive attitude in learning and applying metacognitive strategies and take part in listening practice actively.

Secondly, put more efforts on cognitive strategies training to improve students' listening comprehension. It is significant for teachers to help students who have difficulties in listening comprehension to improve their English listening ability by using cognitive strategies consciously. Teachers are suggested to enlighten the students on listening strategy use by integrating specific cognitive strategies training into teaching design. Teachers could show students how to use cognitive strategies from the following aspects. First of all, make prediction from the questions and items. Before listening, teachers could suggest the students to preview the questions and items to get some clues or hints, then encourage them to guess how the plot develops or what the topic is from their background knowledge. Next, draw an inference from topic sentence. While listening, teachers should direct the students to catch the topic sentence of each paragraph to predict its content in order to get the main idea of listening materials. Moreover, make a logical judgment through conjunctions. Conjunctions are the signal words for the inner logic of semantic units. As long as the listener grasps the conjunctions, it is quite easy to understand the logic of the speaker and judge the tone and opinion of the speaker. Last, launch prediction and association from speaker's tone, intonation, and stress. During listening, every stress and intonation variation reflects the inner thoughts of the character, so students should learn to predict the speaker's opinion and attitude from the stress and intonation. After acquiring the set of cognitive strategies in listening activities, it is important for students to digest and implement them while doing listening practice after class, thus to achieve the goal of improving students' English proficiency in listening.

Thirdly, according to the findings, although there is a rather weak correlation between social-affective strategies and listening proficiency, the application of social-affective strategies should also be reinforced to reduce anxiety effectively. This kind of strategies is always neglected by the students simply because they take listening practice as a mechanical training for exams. Teachers should try their best to create a relaxed and harmonious atmosphere for students and reduce the factors which may cause anxiety as far as possible. For instance, the difficulty of listening exercises could be lowered to let the students feel that English listening is not as difficult as they thought and they can do it well. In this way, students can develop a proper attitude towards it, eliminate anxiety, and develop their own interest and motivation in English learning. Moreover, the traditional mode of teaching listening should turn from quiz and classroom questions to group discussion or team games. Collaboration among students not only enables them to complete listening tasks, but also exchanges their learning experience with each other. It really helps build rapport with classmates and create a good atmosphere for learning. Finally, teachers could tell the students how to deal with negative emotion and help those poor learners to overcome the fear of listening practice. When students feel frustrated in their disappointing results, remind the students to analyze the reason for failure through monologue instead of blame themselves. Remember any progress can motivate you keep at it, and you will become more confident. In a word, teachers should train 
the students to apply social-affective strategies in listening practice in terms of keeping passion and initiative for learning, which will eventually improve their proficiency in English listening.

\section{References}

Bacon, S. M. (1992). The relationship between genders, comprehension, processing strategies, and cognitive and affective response in foreign language listening. The Modern Language Journal, 76, 160-178.

CHEN, X. T., \& ZHENG, M. (2002). English learning strategies. Beijing: Foreign Language Teaching and Research Press.

HUANG, Z. D. (1998). A review of second language/foreign language listening comprehension strategies research. Foreign Language World, 2, 42-46.

JIANG, Z. K. (1994). The relationship between learning strategies and listening comprehension: A report on the survey of the quality of undergraduate students in China. Foreign Language Teaching and Research, 1, 51-58.

LIU, S. L. (1996). Background knowledge and listening strategies: An example of the schema theory. Modern Foreign Languages, 2, 42-45.

LV, C. H. (2001). Training in listening comprehension strategies. Foreign Language Education, 3, 89-92.

O’Malley, J. M., \& Chamot, A. U. (1990). Learning strategies in second language acquisition. Cambridge: Cambridge University Press.

O’Malley, J. M., Chamot, A. U., \& Kupper, L. (1989). Listening comprehension strategies in second language acquisition. Applied Linguistics, 10, 418-437.

O’Malley, J. M., Chamot, A. U., Stewner-Manzanares, G., Russo, R., \& Kupper, L. (1985). Learning strategy applications with students of English as a second language. TESOL Quarterly, 120, 285-296.

Oxford, R. L. (1990). Language learning strategies: What every teacher should know. New York: Newbury House/Harper Collins.

Rivers, W. M., \& Temperly, M. S. (1978). A practical guide to the teaching of English as a second or foreign language. New York: Oxford University Press.

Rost, M., \& Ross, T. (1991). Learner use of strategies in interaction: Typology and teachability. Language Learning, 41, $235-273$.

Skehan, P. (1989). Individual differences in second language learning. London: Edward Arnold.

Vandergrift, L. (1996). Listening comprehension strategies of core French high school student. Canadian Modern Language Review, $52,200-223$.

Vandergrift, L. (1997). The comprehension strategies of second language (French) listeners: A descriptive study. Foreign Language Annuals, 30, 387-409.

WANG, C. M., \& Qi, L. X. (1992). A case study of foreign language listening strategies, In S. C. GUI (Ed.), The psychology of Chinese learners of English. Changsha: Hunan Education Press.

WANG, D. M. (2012). Review and prospective on English teaching of higher vocational education: Review of the 6th National Forum on English Teaching in Higher Vocational Colleges in China. Foreign Language World, 3, 96.

WANG, Y. (2002). A study of the listening strategies employed by non-English majors in China. Foreign Language World, 2, 5-12.

WEN, Q. F. (1995). The differences of learning methods between successful English learners and unsuccessful English learners. Foreign Language Teaching \& Research, 3, 61-66.

WEN, Q. F. (1996a). A study of developmental changes in language learning strategies. Foreign Languages and Their Teaching, 4, 43-46.

WEN, Q. F. (1996b). English learning strategies. Shanghai: Shanghai Foreign Language Education Press. 